AGRARIS: Journal of Agribusiness and Rural Development Research

Vol. 4 No. 1 J anuari -J uni 2018
PUSDIMA RAHMA PRATIWI ${ }^{1 *}$, SISWANTO IMAM SANTOSO², DAN WILUDJ ENG ROESSALI ${ }^{2}$

${ }^{1} J u r u s a n$ Magister Agribisnis, Universitas Diponegoro, Semarang

${ }^{2}$ Fakultas Peternakan dan Pertanian, Universitas Diponegoro, Semarang

Email korespondensi: pusdima.rahma@gmail.com

\section{Tingkat Adopsi Teknologi True Shal- lot Seed di Kecamatan Klambu, Kabupaten Grobogan}

https://doi.org/10.18196/agr.4155

\section{ABSTRACT}

The productivity of shallot in Grobogan Regency is still low because the use of superior varieties is limited. The deployment of superior shallot seed technology that profitable is widely unknown to farmers. This research aims to analyze the adoption rate of true shallot seed (TSS) technology and the influence of internal and external factors of onion farmers on the adoption of TSS technology. The study wasconducted in Klambu District, Grobogan Regency from July to August 2017 by interviewing 100 farmers who selected using multistage sampling. Data were analyzed using the descriptive method and logistic regression. The results showed that the adoption rate of TSS technology in Klambu District, Grobogan Regency was in a high category. Farmer's age, land tenure status, cosmopolitan rate, frequency of interaction with extension agent, and institutional support significantly influenced TSS technology adoption.

Keywords: adoption, farmers, technology, true shallot seed

\section{INTISARI}

Produktivitas bawang merah di Kabupaten Grobogan masih rendah karena penggunaan varietas unggul yang masih terbatas. Penyebaran teknologi benih bawang merah unggul yang menguntungkan belum secara luas diketahui oleh petani. Penelitian ini bertujuan untuk menganalisis tingkat adopsi teknologi true shallot seed (TSS) dan pengaruh faktor internal dan eksternal petani bawang merah terhadap adopsi teknologi TSS. Penelitian dilakukan di Kecamatan Klambu, Kabupaten Grobogan sejak bulan Juli hingga Agustus 2017 dengan mewawancarai 100 petani yang dipilih dengan menggunakan multistage sampling. Data dianalisis menggunakan metode deskripitif dan regresi logistik. Hasil penelitian menunjukkan bahwa tingkat adopsi teknologi TSS di Kecamatan Klambu, Kabupaten Grobogan berada pada kategori tinggi. Umur petani, status kepemilikan lahan, tingkat kekosmopolitan, frekuensi interaksi dengan penyuluh, dan dukungan kelembagaan secara nyata berpengaruh terhadap adopsi teknologi TSS.

Kata Kunci: adopsi, petani bawang merah, teknologi TSS.

\section{PENDAHULUAN}

Bawangmerah merupakan salah satu tanaman sayuran dengan nilai ekonomi tinggi, sehingga banyak petani yang membudidayakannya sebagai usahatani komersial. Walau demikian, manfaat bawang merah sebagai penyedap rasa dan sumber biofarmaka (M erhi, Auger, Rendu, \& Bauvois, 2008), menyebabkan permintaan konsumen terhadap bawang merah terus mengalami peningkatan. Pada tahun 2015-2016 permintaan bawang merah meningkat sebesar 1,83\% (N uryati \& N oviati, 2015). Dalam upaya memenuhi kebutuhan yang semakin tinggi, pemerintah melakukan berbagai macam inovasi baru untuk 
meningkatkan produksi bawang merah, salah satunya melalui penggunaan benih asal biji atau true shallot seed (TSS).

Penggunaan TSS sebagai sumber benih merupakan salah satu alternatif solusi untuk mencukupi kebutuhan benih bermutu. Teknologi TSS diharapkan dapat meningkatkan produktivitas, menyehatkan tanaman, mengefisienkan penggunaan benih, dan memudahkan transportasi sehingga dapat menekan biaya kirim (M ardiyanto, Pangestuti, Prayudi, \& Endrasari, 2017). Penggunaan TSS memiliki beberapa keunggulan, yaitu kebutuhan benih hanya $\pm 7,5 \mathrm{~kg} / \mathrm{ha}$ dibandingkan dengan benih asal umbi $\pm 1,5$ ton/ha; bebas virusdan penyakit tular benih; menghasilkan umbi yang lebih sehat, besar, dan bulat; daya hasil tinggi; hemat biaya produksi (Sumarni, Sumiati, \& Suwandi, 2005); serta bentuk dan ukuran umbi untuk konsumsi relatif lebih seragam (Sulistyaningsih, 2004). Daya simpan TSS mencapai satu tahun, sehingga lebih fleksibel dan dapat ditanam saat dibutuhkan. Proses distribusi lebih mudah dan murah dengan pengemasan yang baik, sehingga tingkat kerusakan sangat kecil (Pangestuti \& Sulistyaningsih, 2011). Produktivitas TSS lebih tinggi yaitu $\pm 24-34$ ton/ha dibandingkan dengan benih asal umbi yaitu $\pm 17,1$ ton/ ha tergantung dengan varietasnya, (Van den Brink \& Basuki, 2012) bahkan mampu mencapai produktivitas hingga 36,242,5 ton/ ha (Pangestuti \& Sulistyaningsih, 2011).

Provinsi Jawa Tengah menempati urutan pertama sebagai daerah penghasil bawang merah terbesar di Indonesia (BPS, 2017). D alam upaya meningkatkan produksi, sejak awal tahun 1990 Balai Penelitian Tanaman Sayuran sudah merintis penggunaan TTS. Pada tahun 2016 teknologi TTS dikembangkan Dinas Pertanian Tanaman Pangan dan H ortikultura (D ipertan TPH ) G robogan dan Balai Pengkajian Teknologi Pertanian (BPTP) Jawa Tengah. Terdapatnya sejumlah petani di Kabupaten G robogan yangtelah memulai menanam TSS, mengindikasikan adanya respon petani yang cukup baik terhadap TSS. Hasil produksinya masih diprioritaskan menjadi benih umbi mini dan belum dijual untuk konsumsi. $\mathrm{H}$ al ini dilakukan agar mereka dapat terbiasa menggunakan umbi mini sebagai sumber benih bermutu, tanpa mengubah teknik budidayanya (M ardiyanto, Pangestuti, Prayudi, \& Endrasari, 2017).

Adopsi merupakan langkah akhir dari prosesmenerapkan pengetahuan inovasi untuk menggunakan dan memanfaatkan inovasi sepenuhnya sebagai cara terbaik dalam mengatasi kebutuhannya. Ketidakjelasan manfaat dan biaya (Pannell, Marshall, Barr, C urtis, Vanclay, \& W ilkinson, 2006) serta karakteristik teknologi (Forbes, Cullen, \& Grout, 2013) dapat mempengaruhi tingkat adopsi. Adopsi teknologi bagi petani ditentukan oleh kebutuhan dan kesesuaian teknologi dengan kondisi biofisik, sosial budaya, serta spesifik lokasi. Keputusan untuk mengadopsi ditentukan dari faktor internal dan eksternal petani (Aditiawati, Rosmiati, \& Sumardi, 2014). Adopsi inovasi bioteknologi oleh petani berhasil meningkatkan pertumbuhan tanaman serealia di lingkungan tadah hujan (Rosegrant, Cai, \& Cline, 2002). Kurangnya pengenalan inovasi teknologi baru pada petani Nigeria membuat produksi dan produktivitas tanaman mereka melambat dan kemiskinan di pedesaan pun meningkat (U aiene, Arndt, \& Masters, 2009); (H ailu, Abrha, \& Weldegiorgis, 2014). Adopsi teknologi dipengaruhi faktor risiko, sarana dan prasarana, serta dukungan kelembagaan pada petani gurem (M ackenzie, 2003); pada kasus lain dipengaruhi oleh jenis kelamin, status kepemilikan lahan, irigasi, akses kredit, dan interaksi dengan penyuluh ( $\mathrm{H}$ ailu, A brha, \& Weldegiorgis, 2014). Perilaku komunikasi, motivasi, dan pendidikan mempengaruhi adopsi teknologi bawang merah di Bantul (Sasongko, W itjaksono, \& H arsoyo, 2014). Pendapatan, dan tingkat kosmopolitan memiliki hubungan sangat nyata terhadap tingkat adopsi teknologi budidaya bawang merah di Tompaso (Manongko, Pakasi, \& Pangemanan, 2017). Tujuan dari penelitian ini adalah untuk menganalisis tingkat adopsi teknologi TSS dan pengaruh faktor internal dan eksternal petani bawang merah terhadap adopsi teknologi TSS.

\section{METODE PENELITIAN}

Penelitian dilakukan di Kecamatan Klambu, Kabupaten G robogan sejak bulan Juli hingga A gustus 2017. Kecamatan Klambu dipilih sebagai lokasi penelitian dengan pertimbangan wilayah tersebut merupakan salah satu daerah perencanaan sentra produksi TSS sejak tahun 2016. Data primer dikumpulkan melalui wawancara menggunakan daftar pertanyaan terstruktur dari 100 sampel petani yang dipilih dengan teknik multistage sampling. Kecamatan Klambu terdiri dari 9 desa, tetapi baru 5 desa yang telah mengadopsi teknologi TSS, sehingga sampel hanya diambil dari 5 desa tersebut. Jumlah sampel ditentukan menggunakan Rumus Slovin (U mar, 2004) dengan nilai galat pendugaan 10\%, sehingga didapatkan hasil yaitu 93 sampel yang dibulatkan menjadi 100 sampel. Jumlah sampel tersebut dialokasikan ke 5 desa yang dijadikan lokasi penelitian(Tabel 1).

Tingkat adopsi dianalisis secara deskripsi, sedangkan faktor internal dan eksternal petani yang mempengaruhi adopsi teknologi TSS dianalisismenggunakan regresi logistik. Tingkat adopsi dihitungmenggunakan rumus sebagai berikut (Santoso, Suryadi, Subagyo, \& Latulung, 2005): 
TABH 1 PसHIUNGANJUMAHSAM田

No Desa Perhitungan Jumlah Sampel

\begin{tabular}{|c|c|c|c|}
\hline N & Dex & Peritunggr & JuntahSanpd \\
\hline 1 & Kandangejo & $\frac{69}{131=} \times 100=52,55$ & 53 \\
\hline 2 & Taunan & $\frac{135}{131:} \times 100=10,28$ & 10 \\
\hline 3 & Kanter & $\frac{191}{131:=} \times 100=15,00$ & 15 \\
\hline 4 & Teles & $\frac{1 / 2}{13]^{175}} \times 100=13,40$ & 13 \\
\hline 5 & Jenegen & $\frac{1}{1312} \times 100=8,76$ & 9 \\
\hline & Junteh & & 100 \\
\hline
\end{tabular}

Nilai Skor $=\frac{\mathrm{P}}{\sum \mathrm{BS}} \times \mathrm{BS}$

keterangan:

P : Persentase petani yang menerapkan komponen teknologi (\%)

BS : Bobot Skor

LBS : Total Bobot Skor dengan klasifikasi tingkat adopsi menggunakan 3 kelas (expert judgment), yaitu:

a. $0,00 \%-44,99 \%=$ klasifikasi adopsi rendah

b. $45,00 \%-64,99 \%=$ =klasifikasi adopsi sedang

c. $65,00 \%-100,00 \%=$ klasifikasi adopsi tinggi

Model Regresi Logistik dirumuskan sebagai berikut (G ujarati, 2003):

$$
\left.\ln \left(\frac{p}{1-p}\right)=\beta_{0}+\beta_{1} X_{1}+\beta_{2} X_{2}+\beta_{3} X_{3}+\beta_{4} X_{4}+\cdot \cdot+\beta_{11} X_{11} \ldots \ldots \ldots . .2\right)
$$

Variabel dependen pada penelitian ini bersifat kategorik, yaitu diberi kode 0 jika petani tidak mengadopsi teknologi TSS dan diberi kode 1 jika mengadopsi. Sementara itu, variabel independen yang diduga mempengaruhi adopsi teknologi TSS meliputi umur $\left(X_{1}\right)$, pendidikan terakhir $\left(X_{2}\right)$, luas lahan $\left(X_{3}\right)$, status kepemilikan lahan $\left(X_{4}\right)$, pendapatan $\left(X_{5}\right)$, kekosmopolitan $\left(X_{6}\right)$, frekuensi interaksi dengan penyuluh $\left(X_{7}\right)$, jenis pengambilan keputusan $\left(X_{8}\right)$, keanggotaan dalam kelompok tani $\left(X_{9}\right)$, ketersediaan sarana dan prasarana $\left(X_{10}\right)$, dan dukungan kelembagaan $\left(X_{11}\right)$ diukur dengan skala yang berbeda-beda sebagaimana ditampilkan pada Lampiran 1.

\section{HASIL DAN PEMBAHASAN \\ KARAKTERISTIK INTERNAL RESPONDEN}

$\mathrm{H}$ asil penelitian menunjukkan $85 \%$ petani berada pada umur produktif (Tabel 2). Petani pada kisaran umur antara 15-55 tahun adalah umur produktif dengan produktivitas kerja tinggi, yang pada umumnya teralokasi untuk beragam aktivitasusahatani (Rahmadona, Fariyanti, \& Burhanuddin, 2015). Petani muda cenderung lebih memiliki semangat untuk tahu apa yang belum diketahui (Suharni, Waluyati, \& Jamhari, 2017) dan berusaha untuk lebih cepat mengadopsi inovasi baru walaupun belum berpengalaman mengenai inovasi tersebut. Petani yang tua sebanyak $15 \%$, akan mengalami penurunan stamina dan produktivitasnya, sehingga mengadopsi teknologi baru akan semakin lama. Petani berumur tua enggan untuk membudidayakan TSS karena dibutuhkan waktu yang lebih lama dibandingkan dengan bawang merah asal umbi.

\section{TABH 2 DAAKABAKIIASTIKINIEANALFEIAN BANANGMEAH}

\begin{tabular}{|c|c|c|c|}
\hline \multicolumn{2}{|c|}{ KádkeisikikItend Petari } & Junteh(Oang) & $(\%)$ \\
\hline \multicolumn{4}{|c|}{ UhorPetai } \\
\hline Sol & $>$ 55thur & 15 & 15 \\
\hline 2 & $36-55$ thun & 72 & 72 \\
\hline 3 & $<36$ thun & 13 & 13 \\
\hline \multicolumn{4}{|c|}{ PenddkanTeadkir } \\
\hline So 1 & TidktanđSC & $\Xi$ & 3 \\
\hline 2 & $\Phi$ & 46 & 46 \\
\hline 3 & SMP & 28 & 28 \\
\hline 4 & SMASMK & 17 & 17 \\
\hline 5 & > SMASMK & 6 & 6 \\
\hline \multicolumn{4}{|c|}{ Leslater } \\
\hline So 1 & $\leq 0,50 \mathrm{ha}$ & $4 \varepsilon$ & $4 \varepsilon$ \\
\hline 2 & $0,51-2,0$ ra & 42 & 42 \\
\hline 3 & $>2,00 \mathrm{ra}$ & 10 & 10 \\
\hline \multicolumn{4}{|c|}{ StaskepenilikanLdan } \\
\hline Sorl & Petari Penyenta & 27 & 27 \\
\hline 2 & Petari Penilik & B & B \\
\hline \multicolumn{4}{|c|}{ PenceptanPetai (Rd/blan) } \\
\hline Sol & Rp1œ000- вp2100,0 & 32 & 32 \\
\hline 2 & вр210001- Рр33300.00 & 27 & 27 \\
\hline 3 & Rр3300001- - p 4500.000 & 23 & 23 \\
\hline 4 & Rp4500001- Pp5 5700,000 & 9 & 9 \\
\hline 5 & $>$ Pp5.700000 & 9 & 9 \\
\hline \multicolumn{4}{|c|}{ KtorsqupditanPetari } \\
\hline Sor0 & Tidekkosmepdit & 12 & 12 \\
\hline 1 & Kosmepdit & 88 & 88 \\
\hline
\end{tabular}

H asil penelitian menunjukkan $51 \%$ petani berada pada pendidikan yang tinggi (e" SM P). Petani dengan pendidikan yang tinggi lebih mudah dalam mencerna ilmu dan teknologi baru (Rahmadona,Fariyanti, \& Burhanuddin, 2015) serta 
lebih tinggi kemampuannya dalam menerima, menyaring, dan menerapkan inovasi baru (Sasongko, W itjaksono, \& H arsoyo, 2014). Pendidikan yang rendah (sebanyak $49 \%$ ) membuat wawasan petani terhadap teknologi menjadi rendah (Astuti, Sugandi, \& Hamdan, 2014). Petani tersebut akan mulai mencoba menanam TSS setelah melihat petani lain berhasil menanamnya.

$\mathrm{H}$ asil penelitian menunjukkan $52 \%$ petani memiliki lahan yang luas ( $>2 \mathrm{ha}$ ), sehingga akan lebih mudah dan lebih cepat untuk mengadopsi teknologi baru, karena adanya kemampuan ekonomi yang lebih baik (Romdon, Supardi, \& Sasongko, 2012). Semakin luas lahan yangdigunakan untuk usahatani, petani semakin termotivasi untuk mengadopsi teknologi baru (Rahmawati, W idjayanthi, \& Raharto, 2010). Petani yang memiliki lahan sempit (sebanyak $48 \%$ ), cenderung untuk tetap mempertahankan pola tanam yang telah ada. Keadaan ini disebabkan karena adanya pemikiran terhadap risiko besar maupun ketidakpastian produksi dan pemasaran yang mungkin akan terjadi jika memilih untuk mengadopsi inovasi baru (Theresia, Fariyanti, \& Tinaprilla, 2016).

Hasil penelitian menunjukkan $73 \%$ petani merupakan petani pemilik. Kegiatan pengolahan lahan petani pemilik bersifat turun temurun, sehingga lebih mudah dalam mengambil keputusan untuk mengadopsi teknologi baru (U krita, M usharyadi, \& Silfia (2011). Berbeda halnya dengan petani penyewa (sebanyak $27 \%$ ) yang harus mendapatkan persetujuan dari pemilik tanah terlebih dahulu, sebelum mencoba atau menggunakan teknologi baru(Suharyanto \& Kariada, 2011).

Budidaya TSS membutuhkan dana yang cukup tinggi saat awal penerapan, tetapi akan memberikan keuntungan yang lebih tinggi dibandingkan dengan bawang merah asal umbi saat panen. $\mathrm{H}$ asil penelitian menunjukkan sebanyak $32 \%$ petani memiliki pendapatan sebesar Rp 1.000.000-Rp 2.100.000. Besarnya pendapatan yang diperoleh akan menjadi pertimbangan dalam mengambil keputusan (Theresia, Fariyanti, \& Tinaprilla, 2016). Semakin tinggi pendapatan maka semakin tinggi keinginan petani untuk mengadopsi teknologi baru (Putri, Astuti, \& Yanti, 2016), karena memiliki penghasilan tinggi untuk mencoba hal baru (Rastiyanto, Surachmanto, \& Pullaila, 2014).

$\mathrm{H}$ asil penelitian menunjukkan $88 \%$ petani merupakan petani kosmopolit. Petani kosmopolit lebih cepat dalam memutuskan untuk mengadopsi inovasi baru walaupun belum mengetahui secara pasti keunggulan dan kehandalan inovasi tersebut. Petani kosmopolit akan menambah wawasan pengetahuannya yang berkenaan dengan usahatani, sehingga dapat meningkatkan pengelolaan usahataninya (Suprayitno, Sumardjo, Gani, \& Sugihen, 2015) dan dapat memilih inovasi terkini secara rasional untuk diterapkan (Erlina \& Kurniasari, 2007). Petani yang tidak kosmopolit (sebanyak $12 \%)$, tidak memiliki keberanian untuk membuka diri terhadap suatu pembaharuan, sehingga dapat memperburuk kondisinya untuk membuat keputusan (A gustina, Zahri, Yazid, \& Yunita, 2017).

\section{KARAKTERISTIK EKSTERNAL RESPONDEN}

Penyuluh dapat meningkatkan minat petani untuk mengadopsi teknologi baru melalui program penyuluhan. Penyuluhan dilakukan sesuai dengan kebutuhan sasaran dalam rangka meningkatkan motivasi petani untuk merubah perilakunya menjadi lebih baik (Lucie, 2005). $\mathrm{H}$ asil penelitian menunjukkan 34\% petani tidak pernah berinteraksi dengan penyuluh (Tabel 3). Kurangnya variasi dalam penyampaian materi penyuluhan menjadikan petani kurang tertarik mengikuti kegiatan penyuluhan (Farfar, 2011). Frekuensi interaksi yang rendah (sebanyak 32\%) disebabkan tidak semua petani mendapat undangan untuk menghadiri penyuluhan dan adanya pengaruh bahasa daerah sehingga membutuhkan juru bicara ( $\mathrm{N}$ isa \& Zain, 2015); (M arsaulina, H erlina, \& Yumiati, 2014). Semakin tinggi frekuensi interaksi dengan penyuluh, sebanyak $34 \%$, petani berinteraksi $7-12$ kali, maka semakin cepat petani mengadopsi inovasi baru ( $N$ arti, 2015).

$\mathrm{H}$ asil penelitian menunjukkan $85 \%$ petani menggunakan jenis keputusan kelompok. Keputusan kelompok lebih baik dan efektif dalam proses penerapan adopsi, tetapi membutuhkan waktu lebih lama dalam mencapai hasil keputusan (Irwandi, Prajarto, \& H aryadi, 2014). Keputusan kelompok lebih baik dalam menyebarkan inovasi baru ke dalam sistem sosial dibandingkan keputusan mandiri, karena adanya kemungkinan distorsi (gangguan) pesan dan perbedaan persepsi yang lebih kecil, serta konsensus yang akan dicapai lebih cepat (H anafi, 1987).

Kelompok tani merupakan forum belajar dan forum mengambil keputusan untuk memperbaiki nasib petani. H asil penelitian menunjukkan $81 \%$ petani ikut serta dalam kelompok tani. Petani yang ikut serta di dalamnya akan memperoleh manfaat dari beberapa kegiatan yang dapat menunjang usahataninya dan dapat meningkatkan potensi serta kemampuan untuk keberhasilan usahataninya ( $\mathrm{H}$ ariadi, 2007). Kelompok tani sangat penting, karena merupakan wadah interaksi antar petani dan forum komunikasi yang demokratis (Rosyadi, 2003). 
TABH 3 DAAKABAKIERSTIKBSTERALETAN BAMANGMEAH

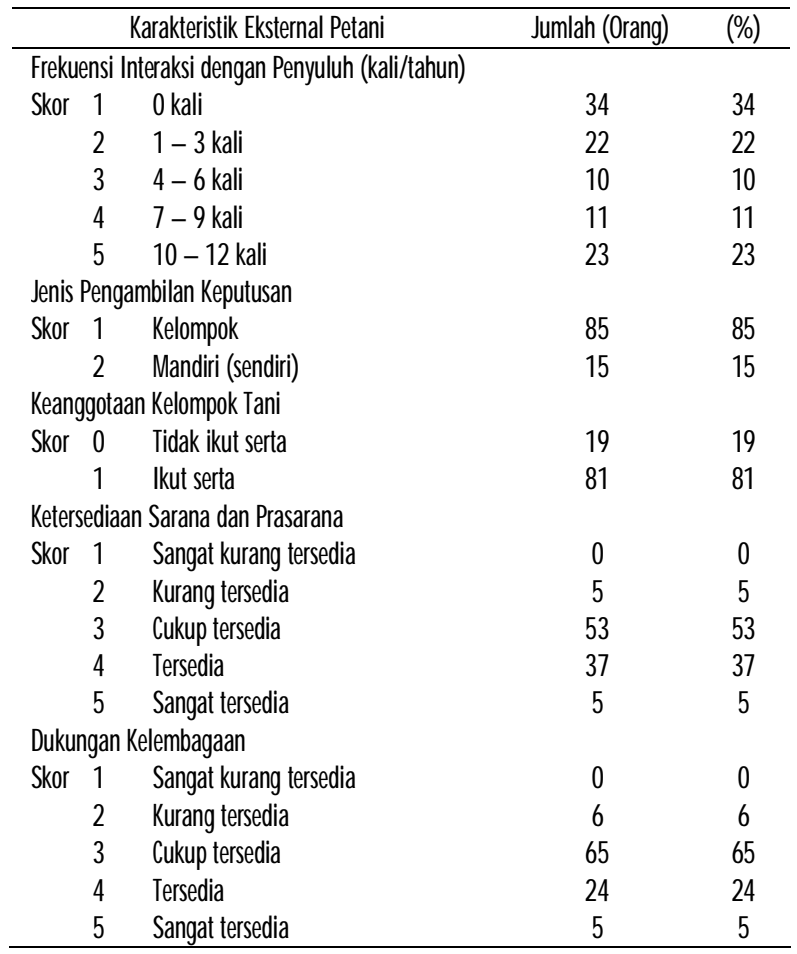

Ketersediaan sarana dan prasarana mendukung kelancaran petani dalam mengadopsi teknologi, sehingga dapat mempengaruhi keputusannya untuk mengadopsi teknologi baru ( $\mathrm{H}$ anafie, 2010). H asil penelitian menunjukkan $53 \%$ petani menyatakan sarana dan prasarana cukup tersedia. Keadaan ini dikarenakan Dinpertan Grobogan telah memberi bantuan sarana dan prasarana berupa $6 \mathrm{~kg}$ benih TSS, 6 ton pupuk organik, dan 15 liter PG PR kepada beberapa Gapoktan di K abupaten G robogan dalam rangka pengenalan TSS (D inpertan G robogan, 2017).

$\mathrm{H}$ asil penelitian menunjukkan $65 \%$ petani menyatakan dukungan kelembagaan cukup tersedia. Ketersediaan kelembagaan seperti kelompok tani dan dukungan pemerintah seperti lembaga penyuluh akan mempercepat penyebaran informasi untuk mempermudah mengadopsi teknologi. Kelompok tani merupakan kelembagaan yang dapat memperkuat posisi petani dalam berhubungan dengan lembaga lainnya, seperti lembaga agroinput dan pemasaran (Priyono, Shiddieqy, Widiyantono, \& Zulfanita, 2015). Penyuluh dapat melibatkan kelompok tani untuk melakukan sosialisasi dan diseminasi teknologi dalam memberdayakan petani sebagai pelaku utama dan pelaku usaha (Indraningsih, 2011).

\section{TINGKAT ADOPSI TEKNOLOGI TSS}

Rerata tingkat adopsi teknologi TSS berdasarkan 12 komponen teknologi di Kecamatan Klambu, Kabupaten Grobogan adalah $86,75 \%$ atau berada pada klasifikasi tinggi (Tabel 4). Hasil tersebut menunjukkan bahwa sebanyak 63 petani yang mengadopsi teknologi TSS di daerah penelitian belum menerapkan seluruh komponen teknologi sesuai anjuran teknis. Dari 12 komponen teknologi TSS yang dikenalkan, hanya terdapat duakomponen yang termasuk dalam klasifikasi sedang dan sisanya berada pada klasifikasi tinggi.

Komponen penggunaan dan pemanfaatan benih berada pada klasifikasi tinggi $(100,00 \%)$. Petani yang mengadopsi komponen tersebut telah mengetahui dan memahami anjuran dasar penanaman TSS (Gambar 1). Komponen perlakuan TSS dengan fungisida berada pada klasifikasi tinggi $(95,24 \%)$. Biji TSS sebelum persemaian dianjurkan untuk diberi perlakuan fungisida, agar TSS tidak terserang penyakit saat persemaian. Petani yang tidak memberi perlakuan sesuai yang dianjurkan (sebanyak 3 orang) mengalami kegagalan. Komponen persiapan untuk persemaian berada pada klasifikasi tinggi (100,00\%). M edia semai untuk TSS berupa campuran arang sekam, kompos pupuk kandang, dan tanah (1:1:1) dengan kedalaman $20 \mathrm{~cm}$.

Komponen pengaturan jarak tanam antar bedengan berada pada klasifikasi tinggi (71,43\%). Jarak antar bedengan yang dianjurkan adalah $1 \mathrm{~m}$ dengan kerapatan semai 2-3

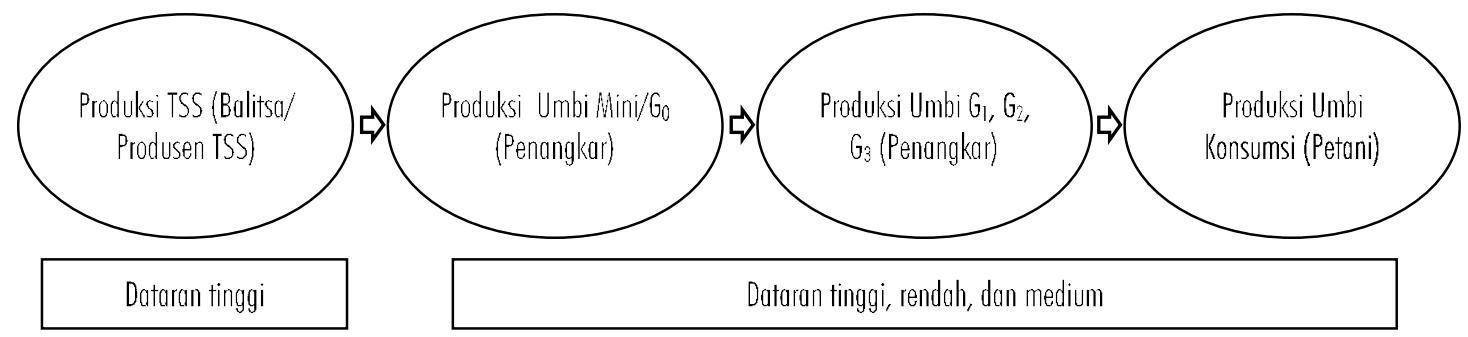

GAMBAR1 MOELALRPFOUKS TSSD TINOKATEIAN

Sumber: (Prayudi, Pangestuti, \& Kusumasari, 2014) 
$\mathrm{gr} / \mathrm{m}^{2}$. Bedengan dibuat dengan lebar $1,2 \mathrm{~m}$; tinggi $30 \mathrm{~cm}$; dan panjang sesuai kondisi lahan, dengan jarak awal dari pinggir bedengan $10 \mathrm{~cm}$ dan jarak antar larikan dalam bedengan $10 \mathrm{~cm}$ (10 larikan/ $\left.\mathrm{m}^{2}\right)$. Sebanyak 18 petani menggunakan jarak antar bedengan 0,5-0,75 $\mathrm{m}$ dan 1,25$1,5 \mathrm{~m}$ dengan kerapatan semai $3-5 \mathrm{gr} / \mathrm{m}^{2}$.

\section{TAB⿴囗十 4 TINOKAADOPS PEIAN TERADAPKOMPONENIENDOC TSS}

\begin{tabular}{|c|c|c|c|c|}
\hline KonporenTekndag & $\begin{array}{l}\text { Bdot } \\
\text { Sta*) }\end{array}$ & $\begin{array}{l}\text { Junteh } \\
\text { Petai }\end{array}$ & $\begin{array}{l}\text { Pesetase } \\
(\%)\end{array}$ & $\begin{array}{c}\mathrm{Nla} \\
\text { Sla**) }\end{array}$ \\
\hline \multicolumn{5}{|l|}{ RNGENANBNHDNN } \\
\hline \multicolumn{5}{|l|}{ INCGAHANTANAH } \\
\hline Perggureanden pertrfatanberih & 3 & $\sigma$ & $100, \infty$ & $7,5 \mathrm{C}$ \\
\hline Perdken TSSdanganfurgisica & 40 & 60 & 9,24 & 9,52 \\
\hline Pesiapenurtkkpesenaian & 30 & 6 & 100,00 & 7,50 \\
\hline \multicolumn{5}{|l|}{ TENNKPENANAMAN } \\
\hline $\begin{array}{l}\text { Pergaturanjarktarematar } \\
\text { beetrgan }\end{array}$ & 3 & 45 & $71,4=$ & 5,36 \\
\hline Pentbetanrunahraugen & 40 & 37 & 5873 & 5,87 \\
\hline 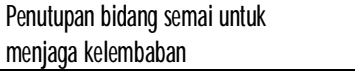 & 3 & 31 & 58,TE & $4,4 C$ \\
\hline \multicolumn{5}{|l|}{ IMMEIHABAANTANAMAN } \\
\hline Perrepkanberintbeng & $\chi$ & 6 & 9,24 & 4,76 \\
\hline Penyirananberintbeng & 20 & 59 & 93,6 & 4,68 \\
\hline Pengendlianglnm & 20 & 6 & 100,00 & 5,00 \\
\hline $\begin{array}{l}\text { Perggreanpestiscasera jeis } \\
\text { clndbsis }\end{array}$ & 2 & 4 & $71,4=$ & 3,51 \\
\hline $\begin{array}{l}\text { Pengendianpenditsesi jeriscan } \\
\text { dbsis }\end{array}$ & 20 & 45 & 71,43 & 3,57 \\
\hline \multicolumn{5}{|l|}{ PANEN } \\
\hline $\begin{array}{l}\text { WAthucknperlakenpenensesui } \\
\text { ajuran }\end{array}$ & 100 & Њ & $100, \infty$ & $\mathbf{2 5 , \infty}$ \\
\hline Tdd & 40 & & & $86 \pi$ \\
\hline
\end{tabular}

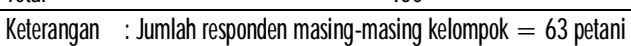

*) Bthetskornæing-mæing komponentedendag drila bercksakenintrangamyaterzaleppodkivitas

**) Nla soo = pesetare/ tad sor xbobetstoryarg besengutan

Komponen pembuatan rumah naungan berada pada klasifikasi sedang $(58,73 \%)$. Petani belum mengetahui fungsi rumah naungan untuk TSS. Petani tidak menggunakan rumah naungan untuk penanaman bawang merah asal umbi. Sebanyak 26 petani belum membuat rumah naungan, sehingga hampir seluruh tanamannya rusak terkena hujan. Rumah naungan terbuat dari plastik transparan (PE) sebagai atapnya dengan ketinggian tiang bambu $2 \mathrm{~m}$ dan 1,5 $\mathrm{m}$ (atap miring) dengan arah atap plastik menghadap ke timur. Beberapa petani melakukan banyak percobaan guna mendapatkan rumah naungan yang dapat digunakan berkalikali, agar kondisi alam atau cuaca yang buruk tidak memberi kerusakan pada rumah naungan. Komponen penutupan bidang semai berada pada klasifikasi sedang $(58,73 \%)$.
Penutupan bidang semai dilakukan untuk menjaga kelembaban tanaman. Benih TSS yang telah disebar merata pada larikan, dilakukan penutupan bedengan dengan daun pisang atau karung goni selama $\pm 4-7$ hari atau hingga benih mulai tumbuh. Sebanyak 26 petani tidak melakukan kegiatan tersebut.

Komponen pemupukan berimbang berada pada klasifikasi tinggi $(95,24 \%)$. Pemupukan yang dianjurkan yaitu pemupukan dasar berupa 10 ton/ha pupuk kandang dan $150 \mathrm{~kg} / \mathrm{ha}$ SP 36, serta pemupukan susulan pertama berupa kocoran N PK (16:16:16) sebanyak $100 \mathrm{~kg} / \mathrm{ha}\left(10 \mathrm{gr} / \mathrm{m}^{2}\right)$ pada tanaman umur 30 hari setelah semai (hss) dan umur 60 hss. Sebanyak tiga petani melakukan pemupukan tidak sesuai anjuran, yaitu memberi pupuk kompos pada tanaman umur 14 hari setelah tanam (hst); dan mengurangi dosis pemupukan dasar, yaitu pupuk kandang menjadi 8 ton/ ha dan SP 36 digantikan dengan pupuk TSP hingga tanaman berumur 14 hst. Komponen penyiraman berimbang berada pada klasifikasi tinggi $(93,65 \%)$. Terdapat empat petani yang melakukan penyiraman hanya 1 kali/hari tanpa memperhatikan cuaca. Penyiraman sesuai anjuran dilakukan 2 kali/ hari, yaitu pada pagi hari (sebelum matahari terbit) dan sore hari. Penyiraman sebaiknya menggunakan spray/ gembor bertekanan rendah, dilakukan sampai tanaman siap panen dengan memperhatikan keadaan cuaca.

Komponen pengendalian gulma berada pada klasifikasi tinggi $(100,00 \%)$. Pengendalian gulma dilakukan secara mekanis, yaitu mencabut gulma secara hati-hati sebanyak 1 kali/ minggu dan 1 kali/ 2 minggu pada tanaman umur $>60$ hst. Komponen penggunaan pestisida dan pengendalian penyakit sesuai jenis dan dosisnya berada pada klasifikasi tinggi $(71,43 \%)$. Sebanyak 18 petani tidak melakukannya sesuai anjuran, yaitu menggunakan pestisida dengan dosis tinggi guna menghindari kerugian serangan ulat, saat musim hujan datang. Pengendalian hama ulat grayak yang berasal dari serangga Spodoptera exiqua men ggunakan Feromon exi yang dipasang 1 minggu sebelum TSS ditanam, sebanyak 5 perangkap/ha dan 20-24 perangkap/ha saat populasi serangga semakin tinggi. Pengendalian hama Liriomyza chinensis dan hama lainnya dilakukan dengan memasang perangkap kuning yang dipasang sebanyak 50 perangkap/ ha setelah TSS ditanam. Perlakuan sesuai anjuran lainnya adalah penyemprotan rutin 1-2 ml/ liter Beauveria/ M etarizium mulai dari tanaman umur 7 hst selama 1 kali/ minggu.

Pengendalian penyakit dilakukan dengan penyemprotan rutin Trichoderma mulai dari tanaman umur 4 hst dengan dosis 1-2 ml/ liter air selama $1 \mathrm{kali} /$ minggu. Pengendalian penyakit bercak ungu atau totol dan penyakit antraknosa 
menggunakan fungisida. Pengendalian penyakit jamur fusarium (moler) dilakukan dengan mencabut tanaman yang terserang dan memberikan kapur dolomit atau fungisida pada bekas tanah untuk mencegah jamur tersebut menyebar ke tanaman lain. Komponen perlakuan panen T SS berada pada klasifikasi adopsi tinggi $(100,00 \%)$. Panen umbi TSS dilakukan saat tanaman berumur 85-90 hari dengan menyesuaikan kondisi fisik di lapangan yaitu dengan cara tanaman dibongkar, dibersihkan, dan diproses sebagai umbi benih dengan masa dormansi 2 bulan sebelum umbi siap ditanam kembali (Gambar 1).

\section{FAKTOR-FAKTOR YANG M EM PENGARUHI ADOPSI TEKNOLOGI TSS}

$\mathrm{H}$ asil uji ketepatan model pada analisis regresi menunjukkan Nagelkerke R Square sebesar 0,417. Artinya, variabel penduga umur, pendidikan, Iuas lahan, status kepemilikan lahan, pendapatan, kekosmopolitan, frekuensi interaksi dengan penyuluh, jenis pengambilan keputusan, keanggotaan kelompok tani, ketersediaan sarana dan prasarana, dan dukungan kelembagaan mempengaruhi keputusan petani untuk mengadopsi teknologi TSS sebesar $41,7 \%$; sedangkan sisanya $58,3 \%$ dipengaruhi oleh variabel lain di luar model. $\mathrm{H}$ asil uji $\mathrm{G}$ menunjukkan signifikansi hitung sebesar 0,000 yang artinya secara simultan variabelvariabel penduga mempengaruhi adopsi teknologi TSS. H asil uji Wald untuk menguji signifikansi parameter dari masingmasing responden (Tabel 5) menunjukan terdapat 5 variabel, yaitu umur, status kepemilikan lahan, kekosmopolitan, frekuensi interaksi dengan penyuluh dan dukungan kelembagaan yang berpengaruh signifikan terhadap keputusan petani untuk mengadopsi teknologi TSS.

Variabel umur memiliki nilai signifikansi sebesar 0,022 yang mengindikasikan pengaruh yang signifikan terhadap adopsi teknologi TSS. Nilai koefisien regresi variabel umur memiliki hubungan negatif, artinya semakin rendah skor variabel umur petani (petani berumur tua) semakin tinggi kemungkinan untuk mengadopsi teknologi TSS. Keadaan tersebut disebabkan karena petani berumur tua lebih memiliki wawasan yang terbuka (Putra, W itjaksono, \& $\mathrm{H}$ arsoyo, 2017) dan memiliki kematangan dalam segi pemikiran untuk dengan bijak memutuskan dalam menerima inovasi baru, sehingga mereka lebih berani untuk menerapkan inovasi baru (Rahmawati, W idjayanthi, \& Raharto, 2010).

Variabel status kepemilikan lahan $\left(X_{4}\right)$ memiliki nilai signifikansi sebesar 0,004 yang mengindikasikan pengaruh yangsignifikan terhadap adopsi teknologi TSS. N ilai koefisien regresi variabel statuskepemilikan lahan memiliki hubungan positif, artinya semakin tinggi skor variabel status kepemilikan lahan (petani pemilik lahan) semakin tinggi kemungkinan untuk mengadopsi teknologi TSS. Petani pemilik sekaligus penggarap lebih mudah dalam menerapkan teknologi yang diintroduksikan (Pratama \& Swastika, 2016). Petani pemilik lahan, lebih efektif dalam mengikuti kegiatan penyuluhan dan lebih mudah dalam memanfaatkan berbagai fasilitas yang disediakan pemerintah baik kredit usahatani, pupuk bersubsidi, maupun bantuan benih (Soemarno, Kartasasmita, \& Hakim, 2010).

\section{TABH 5 HASLANAISSFAKTORFAKTRYANGMEMPNGARU ADOP TENOOG TSS}

\begin{tabular}{|c|c|c|c|c|}
\hline Veriabd & $B$ & h\#d & $\mathrm{Sq}$ & Exo(B) \\
\hline Uherpetai (\rangle$\left._{1}\right)$ & $-1,23=$ & $5,2 x$ & $0,022^{*}$ & 0,291 \\
\hline Perddlkenteakir (\rangle$\left._{2}\right)$ & 0,257 & 0,72 & $0,39=$ & 1,298 \\
\hline Lesitan (\rangle$\left._{3}\right)$ & 0,392 & $0,86=$ & $0,35=$ & 1480 \\
\hline Staskeperilikanlahen $\left(\lambda_{4}\right)$ & $1,7 / \varepsilon$ & 8,136 & $0,004^{*}$ & 5,916 \\
\hline Penchodanpetari (\rangle$\left._{5}\right)$ & 0,04 & 0,032 & $0,85 \mathrm{C}$ & 1,042 \\
\hline Kesonqpditanptari $\left(\lambda_{6}\right)$ & 1,822 & $4,50 E$ & $0,03 * *$ & 6,18 \\
\hline $\begin{array}{l}\text { Freduens intedks clangen } \\
\text { peryluh }\left(X_{x}\right)\end{array}$ & 0,448 & 6,229 & $0,013^{k}$ & 1,564 \\
\hline $\begin{array}{l}\text { Jerispengantilankeptusen } \\
\left(\chi_{8}\right)\end{array}$ & 0,915 & 1,349 & 0,246 & 2,496 \\
\hline $\begin{array}{l}\text { Kenggdankdorpoktai } \\
\left(\left(_{x}\right)\right.\end{array}$ & 0,975 & 1,866 & 0,172 & 2,62 \\
\hline $\begin{array}{l}\text { Ketesedansaradan } \\
\text { pesara }\left(X_{10}\right)\end{array}$ & $-0,158$ & 0,133 & 0,716 & 0,854 \\
\hline Dekungenkentergen $\left(X_{11}\right)$ & $-1,097$ & 5,797 & $0,016^{*}$ & 0,334 \\
\hline Konstata & $-0,049$ & 0,000 & 0,986 & 0,92 \\
\hline
\end{tabular}

Keterangan: * signifikan pada level 0,05

Variabel kekosmopolitan petani $\left(\mathrm{X}_{6}\right)$ memiliki nilai signifikansi sebesar 0,034 yang mengindikasikan pengaruh yangsignifikan terhadap adopsi teknologi TSS. N ilai koefisien regresi variabel kekosmopolitan petani memiliki hubungan positif, sehingga semakin tinggi skor variabel kekosmopolitan petani (petani kosmopolit) semakin tinggi pula kemungkinan untuk mengadopsi teknologi TSS. Petani kosmopolit lebih terbuka untuk menerima inovasi baru, karena mereka memperoleh pengetahuan serta informasi pertanian tidak hanya dari penyuluh; tetapi dari petani yang lebih berhasil di daerah lain, pelatihan pertanian, membaca koran, mendengarkan radio, atau media informasi lainnya (Yahya, 2016). Semakin petani kosmopolit maka akan semakin tinggi keinginan petani untuk mengubah sesuatu yangkonvensional menjadi modern (Putri, Astuti, \& Nuri, 2016).

Variabel frekuensi interaksi dengan penyuluh $\left(X_{7}\right)$ memiliki nilai signifikansi sebesar 0,013 yang mengin- 
dikasikan pengaruh yangsignifikan terhadap adopsi teknologi TSS. N ilai koefisien regresi variabel frekuensi interaksi dengan penyuluh memiliki hubungan positif, sehingga semakin tinggi skor variabel frekuensi interaksi dengan penyuluh (sering berinteraksi dengan penyuluh) semakin tinggi pula kemungkinan untuk mengadopsi teknologi TSS. Semakin tinggi frekuensi petani mengikuti penyuluhan maka keberhasilan penyuluhan yang disampaikan semakin tinggi ( $N$ arti, 2015). Frekuensi petani dalam mengikuti penyuluhan dapat meningkat karena penyampaian yang menarik dan tidak membosankan, serta yang disampaikan benar-benar bermanfaat bagi mereka. Inovasi teknologi sering gagal diadopsi petani karena tidak diterapkan secara benar, sehingga membutuhkan pengetahuan dan keterampilan khusus yang dapat diterapkan melalui penyuluhan(Van den Ban \& H awkins, 2005). Penyuluhan dapat dijadikan sarana yang efektif dalam mengarahkan petani guna menerapkan teknologi TSS secara lengkap.

Variabel dukungan kelembagaan $\left(X_{11}\right)$ memiliki nilai signifikansi sebesar 0,016 yang mengindikasikan pengaruh yangsignifikan terhadap adopsi teknologi TSS. N ilai koefisien regresi variabel dukungan kelembagaan memiliki hubungan negatif, sehingga semakin tinggi skor variabel dukungan kelembagaan (semakin sangat tersedia) maka semakin rendah kemungkinan untuk mengadopsi teknologi TSS. Keadaan ini disebabkan karena kelembagaan pertanian di daerah penelitian, walaupun cukup tersedia, kurang berfungsi dengan baik, sehingga petani terbiasa menjadi kosmopolit. Pada pembentukan kel embagaan yang tidak dilakukan secara partisipatif, petani penerima manfaat ditempatkan sebagai aktor yang menjalankan kelembagaan tersebut (Satya \& Aminah, 2009). Dalam kondisi demikian, kelembagaan yang terbentuk kurang mengakomodasi potensi dan kepentingan petani. Misalnya keberadaan kelompok tani sebagian besar hanya digunakan untuk mempermudah penyuluh dan lembaga terkait lainnya dalam memberi bantuan sarana dan prasarana.

\section{KESIMPULAN}

Tingkat adopsi teknologi TSS di Kecamatan Klambu, Kabupaten $\mathrm{G}$ robogan secara umum berada pada klasifikasi tinggi $(86,75 \%)$. Tingkat penerapan teknologi yang paling tinggi $(100 \%)$ terjadi pada komponen penggunaan dan pemanfaatan benih, persiapan persemaian, pengendalian gulma, serta waktu dan perlakuan panen; sedangkan tingkat penerapan teknologi yang paling rendah $(58,73 \%)$ terjadi pada komponen pembuatan rumah naungan dan penutupan bidang semai. Secara simultan, faktor internal dan eksternal berpengaruh terhadap adopsi teknologi TSS di Kecamatan Klambu, Kabupaten Grobogan. Secara parsial, faktor yang mempengaruhi adopsi teknologi TSS adalah umur, status kepemilikan Iahan, kekosmopolitan petani, frekuensi interaksi dengan penyuluh, dan dukungan kelembagaan.

Implikasinya,untuk mengefektifkan dan meningkatkan tingkat adopsi teknologi TSS, hendaknya: i) petani perlu diberi motivasi agar lebih aktif dalam kegiatan penyuluhan khususnya mengenai teknologi pertanian; ii) penyuluh pertanian harus lebih memahami kebutuhan petani agar yang disampaikan sesuai kebutuhannya, dan petani tertarik pada kegiatan penyuluhan; iii) pemerintah hendaknya meningkatkan sekolah lapang di pedesaan, karena kebanyakan petani di pedesaan lebih percaya kepada sekolah lapang; serta iv) perlu penelitian lebih lanjut mengenai jumlah waktu yang dibutuhkan dalam proses atau tahapan adopsi teknologi TSS.

\section{DAFTAR PUSTAKA}

Aditiawati, P., Rosmiati, M., \& Sumardi, D. (2014). Persepsi Petani terhadap Inovasi Teknologi Pestisida Nabati Limbah Tembakau (Suatu Kasus pada Petani Tembakau di Kabupaten Sumedang). Sosiohumaniora, 16(2), 184-192. https://doi.org/10.24198/sosiohumaniora.v16i2.5731

Agustina, F., Zahri, I., Yazid, M., \& Yunita, Y. (2017). Determinant Factors of Agricultural Extension Competence in The Implementation of Good Agricultural Practices in Bangka, Belitung Province. RJOAS, 9(69), 231238. https://doi.org/10.18551/rjoas.2017-09.29

Astuti, U. P., Sugandi, D., \& Hamdan. (2014). Faktor-Faktor yang Memengaruhi Adopsi Petani terhadap Inovasi Teknologi Jeruk Gerga Lebong Di Provinsi Bengkulu. In Prosiding Perlindungan dan Pemberdayaan Pertanian dalam Rangka Pencapaian Kemandirian Pangan Nasional dan Peningkatan Kesejahteraan Petani (pp. 79-85). Bengkulu.

BPS. (2017). Statistik Pertanian Hortikultura Jawa Tengah Tahun 20112015. Retrieved from http://hortikultura.pertanian.go.id.

Dinpertan Grobogan. (2017). Bantuan Pengembangan Teknologi Produksi Umbi Mini Bawang Merah Asal Biji (TSS). Retrieved from https:// dinpertangrobogan.com.

Erlina, M. D., \& Kurniasari, N. (2007). Adopsi Teknologi Palka Berinsulasi untuk Penanganan Ikan Segar Di Pelabuhan Ratu, Sukabumi. Jurnal Perikanan, IX(2), 241-253.

Far-far, R. A. (2011). Pemanfaatan Sumber Informasi Usahatani oleh Petani Sayuran di Desa Waiheru Kota Ambon. Jurnal Ilmiah Agribisnis Dan Perikanan, 4(2), 38-46.

Forbes, S. L., Cullen, R., \& Grout, R. (2013). Adoption of Environmental Innovations: Analysis from The Waipara W ine Industry. W ine Economics and Policy, 2(1), 11-18. https://doi.org/10.1016/j.wep.2013.02.001

Gujarati, D. N. (2003). Ekonometri Dasar. (Z. Sumarno, Ed.). Jakarta: Erlangga.

Hailu, B. K., Abrha, B. K., \& Weldegiorgis, K. A. (2014). Adoption and Impact of Agricultural Technologies on Farm Income: Evidence From Southern Tigray, Northern Ethiopia. International Journal of Food and Agricultural Economics, 2(4), 91-106.

Hanafi, A. (1987). Memasyarakatkan Ide-Ide Baru. Surabaya: Usaha 
Nasional.

Hanafie, R. (2010). Pengantar Ekonomi Pertanian. Yogyakarta: CV Andi Offset.

Hariadi, S. S. (2007). Kelompok Tani Sebagai Basis Ketahanan Pangan. Jurnal IImu-IImu Pertanian, 3(2), 79-86.

Hasan, I. (2004). Pokok-Pokok Materi Teori Pengambilan Keputusan. (M. S. Khadafi, Ed.) (2nd ed.). Jakarta: Ghalia Indonesia.

Indraningsih, K. S. (2011). Pengaruh Penyuluhan Terhadap Keputusan Petani dalam Adopsi Inovasi Teknologi Usahatani Terpadu. Jurnal Agro Ekonomi, 29(1), 1-24.

Irwandi, D., Prajarto, N., \& Haryadi, F. T. (2014). Hubungan dan Pengaruh antara Karakteristik Petani dan Penyuluh Partisipatif dengan Sikap Petani Lokal dalam Adopsi Inovasi Padi di Lahan Pasang Surut Kalimantan Tengah. Agrica Ekstensia, 8(2), 75-98.

Lucie, S. (2005). Teknik Penyuluhan \& Pemberdayaan M asyarakat. Jakarta: Ghalia Indonesia.

Mackenzie, F. D. (2003). Innovation in Natural Resource Management. The Role of Property Rights and Collective Action in Developing Countries. Land Use Policy, 20(3), 294-295.

Manongko, A., Pakasi, C. B. D., \& Pangemanan, L. (2017). Hubungan Karakteristik Petani dan Tingkat Adopsi Teknologi pada Usahatani Bawang Merah Di Desa Tonsewer, Kecamatan Tompaso. Agri-Sosio Ekonomi Unsrat, 13(2A), 35-46.

Mardiyanto, T. C., Pangestuti, R., Prayudi, B., \& Endrasari, R. (2017). Persepsi Petani Terhadap Inovasi Produksi Umbi M ini Bawanng Merah Asal Biji (True Seed of Shallot/TSS) Ramah Lingkungan Di Kabupaten Grobogan. Jurnal Ilmu-IImu Pertanian, 24(1), 41-53.

Marsaulina, M ., Herlina, \& Yumiati, Y. (2014). Persepsi Petani Padi Terhadap Kegiatan Penyuluhan Pertanian Di Desa Sukarami, Kelurahan Taba Penanjung, Kabupaten Bengkulu Tengah. Agritepa, I(1), 27-35.

Merhi, F., Auger, J., Rendu, F., \& Bauvois, B. (2008). Allium Compounds, Dipropyl and Dimethyl Thiosulfinates as Antiproliferative and Differentiating Agents of Human Acute Myeloid Leukemia Cell Lines. Bioloigics: Targets \& Therapy, 2(4), 885-895.

Narti, S. (2015). Hubungan Karakteristik Petani dengan Efektivitas Komunikasi Penyuluhan Pertanian dalam Program SL-PTT (Kasus Kelompok Tani di Kecamatan Kerkap Kabupaten Bengkulu Utara), 2(2), 40-52.

Nisa, N. K., \& Zain, I. M. (2015). Motivasi Petani dalam Menanam Komoditas pada Daerah Lumbung Padi Di Kabupaten Gresik. Swara Bhumi, 3(3), 80-90.

Nuryati, L., \& Noviati. (2015). Outlook Komoditas Pertanian Subsektor Hortikultura (Bawang Merah). Pusat Data dan Sistem Informasi Pertanian Kementerian Pertanian. Jakarta.

Pangestuti, R., \& Sulistyaningsih, E. (2011). Potensi Penggunaan True Seed Shallot (TSS) Sebagai Sumber Benih Bawang Merah Di Indonesia. In Prosiding Semiloka Nasional Dukungan Agro-Inovasi Untuk Pemberdayaan Petani, Kerjasama UNDIP, BPTP Jateng, dan Pemprov Jateng (pp. 258-266). Yogyakarta: Program Studi Agronomi, Fakultas Pertanian, Universitas Gajah Mada.

Pannell, D. J., Marshall, G. R., Barr, N., Curtis, A., Vanclay, F., \& Wilkinson, R. (2006). Understanding and Promoting Adoption of Conservation Practices by Rural Landholders. Australian Journal of Experimental Agriculture, 46(11), 1407-1424. https://doi.org/10.1071/EA05037

Pratama, D., \& Swastika, S. (2016). Persepsi Petani Terhadap Teknologi Budidaya Bawang Merah pada Lahan Kering di Kecamatan Tapung, Kampar, Provinsi Riau. Buletin Inovasi Pertanian, 2(1), 6-12.

Prayudi, B., Pangestuti, R., \& Kusumasari, A. C. (2014). Produksi Umbi M ini Bawang Merah Asal True Shallot Seed (TSS). In Prosiding Inovasi Hortikultura Pengungkit Peningkatan Pendapatan Rakyat (pp. 35-44).
Jawa Tengah: BPTP Jawa Tengah.

Priyono, Shiddieqy, M. I., W idiyantono, D., \& Zulfanita. (2015). Hubungan Kausal antara Tingkat Penguasaan Teknologi, Dukungan Kelembagaan, dan Peran Penyuluh terhadap Adopsi Integrasi Ternak-Tanaman. Informatika Pertanian, 24(2), 141-148.

Putra, A. M. D. D., Witjaksono, R., \& Harsoyo. (2017). Respons Petani terhadap Teknologi Pengendalian Penyakit Busuk Buah dengan Agens Hayati Di Kawasan Agrowisata Desa Serang, Kecamatan Karangreja, Kabupaten Purbalingga. Berkala IImiah Agribisnis AGRIDEVINA, 6(1), 27-42.

Putri, R. E., Astuti, L. T. W., \& Yanti, N. (2016). Adopsi Petani terhadap Teknologi Pengendalian Jamur Akar Putih pada Tanaman Karet (Hevea Brasilliensis Muel. Arg) Di Kejuruan Muda - Aceh Tamiang. Agrica Ekstensia, 10(2), 8-18.

Rahmadona, L., Fariyanti, A., \& Burhanuddin. (2015). Analisis Pendapatan Usahatani bawang Merah di Kabupaten Majalengka. AGRISE, XV(2), 72-84.

Rahmawati, D. R., Widjayanthi, L., \& Raharto, S. (2010). Tingkat Adopsi Teknologi Program Prima Tani dan Penguatan Kelembagaan dengan PT Tri Sari Usahatani. J-SEP, 4(1), 1-14.

Rastiyanto, E., Surachmanto, A., \& Pullaila, A. (2014). Adopsi Teknologi Pertanian Organik dalam Pemanfaatan Lahan Pekarangan Perkotaan Di Kota Serang, Provinsi Banten. Buletin Ikatan, 4(1), 39-47.

Romdon, A. S., Supardi, S., \& Sasongko, L. A. (2012). Kajian Tingkat Adopsi Teknologi pada Pengelolaan Tanaman Terpadu (PTT) Padi Sawah (Oryza sativa L) Di Kecamatan Boja, Kabupaten Kendal. Jurnal IImu-IImu Pertanian, 8(1), 42-60.

Rosegrant, M. W., Cai, X., \& Cline, S. (2002). World Water and Food to 2025: Dealing with Scarcity. Food Policy. https://doi.org/10.1098/ rstb.2005.1744

Rosyadi, S. (2003). Paradigma Baru Manajemen Pembangunan. Bogor: IPB Press.

Santoso, P., Suryadi, A., Subagyo, H., \& Latulung, B. V. (2005). Dampak Teknologi Sistem Usaha Pertanian Padi Terhadap Peningkatan Produksi dan Pendapatan Usahatani Di Jawa Timur. Jurnal Pengkajian Dan Pengembangan Teknologi Pertanian, 8(1), 15-28.

Sasongko, W. A., Witjaksono, R., \& Harsoyo. (2014). Pengaruh Perilaku Komunikasi terhadap Sikap dan Adopsi Teknologi Budidaya Bawang Merah Di Lahan Pasir Pantai Kecamatan Sanden, Kabupaten Bantul. Agro Ekonomi, 24(1), 35-43.

Satya, G., \& Aminah, M. (2009). Dominant Factors on Social Institution Establishment. Forum Penelitian Agro Ekonomi, 27(1), 29-41.

Soemarno, Kartasasmita, U. G., \& Hakim, L. (2010). Pengelolaan Lahan Sawah dan Reorientasi Target Alih Teknologi Usahatani Padi Di Jawa. IPTEK Tanaman Pangan, 5(2), 126-145.

Suharni, Waluyati, L. R., \& Jamhari. (2017). Aplikasi Good Agriculture Practices (GAP) Bawang Merah Kecamatan di Kabupaten Bantul. Agro Ekonomi, 28(1), 48-63.

Suharyanto, \& Kariada, I. K. (2011). Kajian Adopsi Penerapan Teknologi Pupuk Organik Kascing Di Daerah Sentra Produksi Sayuran Kabupaten Tabanan. Jurnal Pengkajian Dan Pengembangan Teknologi Pertanian, 14(1), 28-39.

Sulistyaningsih, E. (2004). Fertilitas Tanaman Bawang Merah Doubled Haploid. Ilmu Pertanian, 11(1), 1-6.

Sumarni, N., Sumiati, E., \& Suwandi. (2005). Pengaruh Kerapatan Tanaman dan Aplikasi Zat Pengatur Tumbuh terhadap Produksi Umbi Bibit Bawang Merah Asal Biji Kultivar. J. Hort., 15(3), 208-214.

Suprayitno, A. R., Sumardjo, S., Gani, S. D., \& Sugihen, G. B. (2015). Dukungan Lingkungan Sosial Budaya terhadap Kemampuan Petani dalam Pengelolaan Hutan Kemiri di Kabupaten M aros Provinsi Sulawesi 
Selatan. Jurnal Penyuluhan, 8(1), 1-14.

Theresia, V., Fariyanti, A., \& Tinaprilla, N. (2016). Pengambilan Keputusan Petani Terhadap Penggunaan Benih Bawang Merah Lokal dan Impor di Kabupaten Cirebon, Jawa Barat. AGRARIS: Journal of Agribusiness and Rural Development Research, 2(1), 50-60. https://doi.org/10.18196/agr.2125

Uaiene, R., Arndt, C., \& Masters, W. (2009). Determinants of agricultural technology adoption in Mozambique. National Directorate of Studies and Policy Analysis, (Ministry of Planning and Development, Republic of Mozambique), 1-31. Retrieved from http://196.46.4.208/gest/documents/ 67E_AgTechAdoptionM oz.pdf

Ukrita, I., Musharyadi, F., \& Silfia. (2011). Analisa Prilaku Petani dalam Penerapan Penanaman Padi Metode SRI (The System Rice of Intensification) (Kasus: Kelompok Tani Sawah Bandang di Kanagarian Koto Tuo, Kecamatan Harau, Kabupaten Limapuluh Kota). Jurnal Penelitian Lumbung, 10(2), 119-127.

Umar, H. (2004). Metode Penelitian untuk Skripsi dan Tesis Bisnis. Jakarta: Raja Grafindo Persada.

Van den Ban, A. W., \& Hawkins, H. S. (2005). Penyuluhan Pertanian. (A. D. Herdiasti, Ed.). Yogyakarta: Kanisius. Van den Brink, L., \& Basuki, R. S. (2012). Production of True Seed Shallots In Indonesia. Acta Horticulturae, 958, 115-120. https://doi.org/10.17660/ ActaHortic.2012.958.12

Yahya, M. (2016). Faktor-Faktor yang Mempengaruhi terhadap Adopsi Petani dalam Pengelolaan Tanaman Terpadu Padi Sawah Di Kabupaten Deli Serdang, Sumatera Utara. Agrica Ekstensia, 10(2), 1-7.

\section{LAMPRAN1 LEKRPS VARAB\# INDEENDENPENIT/N}

\begin{tabular}{|c|c|c|c|}
\hline Natai & $\begin{array}{l}\text { Veriabd } \\
\text { Inckpenden }\end{array}$ & So & Kategai \\
\hline$\lambda_{1}$ & Uherptari & $\begin{array}{l}1 \\
2 \\
3\end{array}$ & $\begin{array}{l}\text { Uher > 55tar } \\
\text { Unor36-55tann } \\
\text { Uher < 36tan }\end{array}$ \\
\hline$\lambda_{2}$ & $\begin{array}{l}\text { Penddken } \\
\text { terktir }\end{array}$ & $\begin{array}{l}1 \\
2 \\
3 \\
4 \\
5\end{array}$ & $\begin{array}{l}\text { TidktantS } \\
\text { SD } \\
\text { SMP } \\
\text { SMASMK } \\
>\text { SMASMK }\end{array}$ \\
\hline$\gamma_{3}$ & Leslaher & $\begin{array}{l}1 \\
2 \\
3\end{array}$ & $\begin{array}{l}\text { Luas lahan } \leq 0,50 \mathrm{ha} \\
\text { Lesladan0,51-2,00ha } \\
\text { Leslahan }>2,00 \mathrm{ha}\end{array}$ \\
\hline $\bar{X}$ & $\begin{array}{l}\text { Staus } \\
\text { keperilikan } \\
\text { lahen }\end{array}$ & $\begin{array}{l}1 \\
2\end{array}$ & $\begin{array}{l}\text { Petari penent } \\
\text { Petari perilik }\end{array}$ \\
\hline$x_{5}$ & $\begin{array}{l}\text { Pendepotan } \\
\text { (Rplalan) }\end{array}$ & $\begin{array}{l}1 \\
2 \\
3 \\
4 \\
5\end{array}$ & 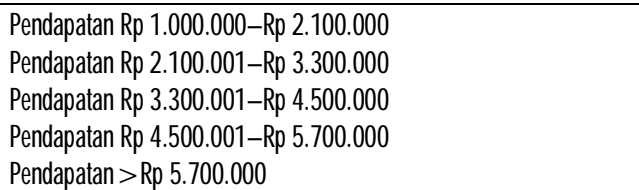 \\
\hline$\lambda_{6}$ & $\begin{array}{l}\text { Kéosmepdi } \\
\text { tanptari }\end{array}$ & $C$ & 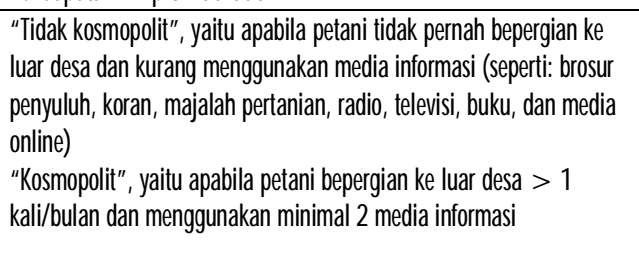 \\
\hline$\rangle_{7}$ & $\begin{array}{l}\text { Frekens } \\
\text { inteaks } \\
\text { dergen } \\
\text { penyluh } \\
\text { (kdi/tan) }\end{array}$ & $\begin{array}{l}1 \\
2 \\
3 \\
4 \\
5\end{array}$ & $\begin{array}{l}0 k \mathrm{ki} \\
1-3 \mathrm{kdi} \\
4-6 \mathrm{kdi} \\
7-9 \mathrm{kdi} \\
10-12 \mathrm{kdi}\end{array}$ \\
\hline$x_{8}$ & $\begin{array}{l}\text { Jeis } \\
\text { pergentila } \\
\text { nkeatusan }\end{array}$ & 2 & 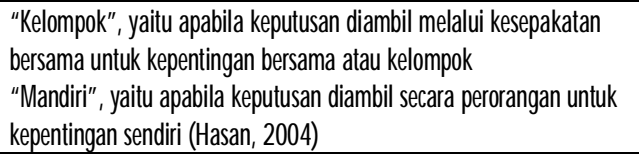 \\
\hline$\lambda_{9}$ & $\begin{array}{l}\text { Keanggta } \\
\text { nkdanpok } \\
\text { tai }\end{array}$ & $\begin{array}{l}C \\
1\end{array}$ & $\begin{array}{l}\text { Tickikiktanpoktai } \\
\text { Mejad anggakedonpoktai }\end{array}$ \\
\hline$\lambda_{10}$ & $\begin{array}{l}\text { Ketesedæ } \\
\text { nsarara } \\
\text { ckn } \\
\text { pasara }\end{array}$ & $\begin{array}{l}1 \\
2 \\
3 \\
4 \\
5\end{array}$ & 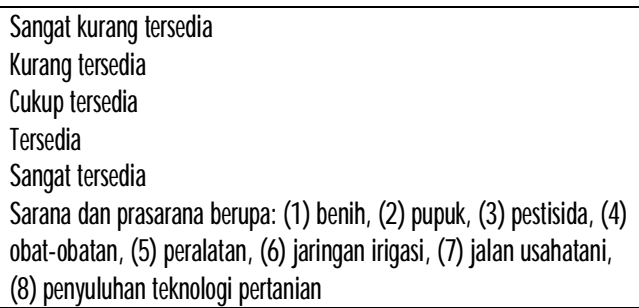 \\
\hline$\lambda_{11}$ & $\begin{array}{l}\text { Dekungen } \\
\text { kdentragea } \\
\mathrm{n}\end{array}$ & $\begin{array}{l}1 \\
2 \\
3 \\
4 \\
5\end{array}$ & 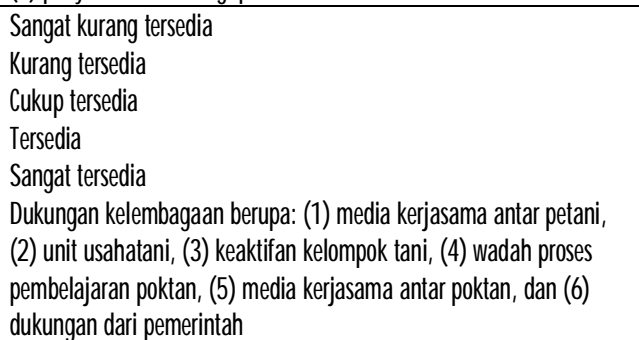 \\
\hline
\end{tabular}

